\section{DE DE GRUYTER OPEN}

Journal of Intercultural Management

Vol. 8 | No. 1 | January 2016 | pp. 71-89

DOI 10.1515/joim-2016-0004

\title{
Edyta Łyszkowska
}

edyta.lyszkowska@gmail.com

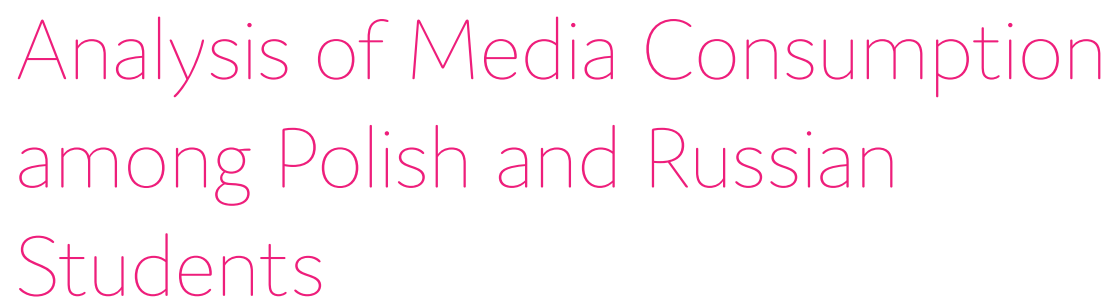

\section{Abstract:}

Living in the contemporary world the man adapts his knowledge and capabilities to various technological forms which are imposed on him as a result of technological progress and development. Younger and younger generations use technological innovations more and more smoothly, living with them almost round-the-clock. The topic of this paper is media consumption by the students. The paper describes surveys of the consumption of TV, internet and other media (e.g. mobile telephony) by the Polish and Russian students and analyses the purpose of their use in their private lives and in student work. In young generations the borderlines between real and virtual worlds tend to become more and more blurred because of growing consumption of spare time. Media consumption has its numerous advantages and disadvantages. The technological development is made at the expense of addictions of young people and lower labour efficiency. This issue is addressed by more and more European countries. On the other hand, smooth consumption of new media creates a lot of interesting opportunities and allows to tap hidden potential of the worker to the ben- 
efit of the company he works for. It turns out that Poland and Russia have a lot in common. The surveys show that a lot of similarities are in media consumption, since both Polish and Russian students tend to spend more of their spare time with the media. Some differences are driven by various degrees of individual media consumption and by their popularity.

\section{Key words:}

new media, media consumption, television, the Internet, mobile phone, intercultural studies, student life.

\section{Introduction}

$21^{\text {st }}$ century is the time of technological progress and development that yields solutions that support faster and more cost-effective communication in the business world. Therefore every human being living in the contemporary world has to learn how to live with the media. Various facets of life (social, professional and personal) agile usage of technological knowledge. Students are an exceptional group because of the type of learning induced by courses at universities and the way of spending their spare time. Some Internet sites offers special tools which allow students to enhance their learning and improve communication skills (Brydolf, 2009, p. 4). They consume more new technologies than other individuals. Nowadays a young man with a tablet, earphones and a mobile phone in his hand constantly connected to the Internet commenting posts is quite a common view. According to a Nielsen Media Research study, approximately 25 $\%$ students' time on the Internet is presently consumed on social media (Jacobsen, Forste, 2011, p. 275). Being online, instantly responding to every new message is a part of modern social life. It is a dominant feature of new generations' lifestyle (Gerlich, Browning, Westermann, 2010, p. 35-41). This feature depicts contemporary identity of a young person. This feature defines also a new approach to marketing strategy, which can be noticed on the basis of McKinsey 7S Framework (Landowska, 2012). The dissemi- 
nation of electronic media, which was proven by McKinsey surveys, calls for the development of new selling and marketing solutions. The one-way communication model was replaced with two-way communication model, which forces companies to be constantly present on the Web via Web fora and social media. Another example is building high product awareness using model of D. Aaker (Dębski, 2013, p. 44).

Meanwhile the technological developments, which are used by the human being on everyday basis, cannot be treated only as contemporary gadgets. New communication tools lead to the creation of the new generation of people who use other communication methods, other communication standards, other values and thus they create a brand new social quality (Szafraniec, 2012, p. 29). This new social quality translates into flexible using communication tools in further students work. Frequently members of teams may consist of people working in other branches, even on various continents without the necessity of physical face to face contact using teleconferences and other on-line contacts are carried out remotely in most multinational companies'. Thanks to such solutions the company makes substantial savings because of cutting business travel and accommodation costs.

Statistics showing dynamic Internet growth compared to other media are the proof of how quickly new technologies conquer the world. It took radio 38 years to reach 50 million audience, television - 13 years, cable television - 10 years, whereas Internet needed barely 4 years. This phenomenon has been further accelerated in social media: Facebook gathered the audience of 100 million users just in 9 months and it is used by 1.11 billion people on a monthly basis (United Nations Cyberschoolbus, 2013). It is estimated that currently there are 3.2 billion Web users (ICT Fact \& Figures, 2015, p. 1), which indicates an astonishing feature of new com-

1. In corporate jargon they are dubbed "conf-calls". 
munication forms, which are characterized by global reach, density and frequency contacts among people.

According to the World Project Poland 2013 Report in the 15+ age group of respondents, 62\% of Poles use Internet and spent 15.7 hours on the Web per week. Respectively, television is watched for 13 hours per week, radio is listened to for 12.2 hours per week, whereas other media (press) constitute for 2.5 hours per week. Moreover, 31\% of Internet users own a Smartphone, whereas 12\% own a tablet. 7\% of Internet users have at least 3 devices connected to the Internet in their households (World Internet Project Poland 2013).

This paper presents the main findings of intercultural studies carried out on Polish and Russian students. The area of interest was narrowed to the use of new media (Internet, television, smartphones) and application of the new media at Polish and Russian students' work, studying and personal life. Their view translates into employers' approach and better understanding of organisational culture prevailing in Poland and Russia.

One of the vital questions in relation to the change of communication channels and methods for searching information in media is: "What information do the students search for in media channels?"

According to P. Chocholska and M. Osipczuk students search for information in their fields of study, they download free textbooks, search for final grade paper information or examination questions. Some students play games as a form of distraction from problems such as unhappy love life, uncertainty about the selected field of study, problems with their colleagues or family. Under such circumstances a young man escapes from the emotional world to the fictional reality and consequently he avoids his own emotions. Internet is a source of all information, base for development and way of learning about the world. Thanks to the Web access, students have a chance to get familiar with the views of other people, can develop their personality. The lack of Web access would deprive 20-year-olds of knowledge about contemporary world, professional and life opportunities (2009, pp. 35-36). 
The new technology consumption in Poland is highly diversified, which was observed by Janusz Czapiński in his 2013 Social Diagnosis. This claim is confirmed by K. Szafraniec who termed this as "digital divide" that is people who find their place in the world of digital media or people who are excluded from this world. The digital user of new media is young, well educated, living in a big city, whereas the excluded individual is a person deprived of access and lacks competencies necessary to enjoy new technologies and hardware, which is the source of symbolic and communication exclusion (p. 33). The digital user meets the criteria of surveyed Polish and Russian students.

Tough relations between Poland and Russia in historical, political and social terms have undoubtedly been a barrier in mutual contacts. Therefore observation and comparison of opinions, behaviours and everyday life of Poles and Russians is an extremely interesting aspect of these studies. Are these two neighbouring nations indeed so different or perhaps they have something in common e.g. the consumption of modern technologies?

\section{Survey methodology}

In 2013 there was carried out a survey concerning aspirations, dreams, lifestyle and life objectives of Polish and Russian students ${ }^{2}$. The researchers from both countries were interested in the opinions and views of the students on everyday life aspects vital to them, on their aspirations and future plans. The survey was designed by the project authors as a co-operation platform for researchers from selected Polish and Russian universities. The survey findings were used to carry out a comparative study of opinions and views of students in both countries on the issues covered by the scope of survey.

\footnotetext{
2. The survey team consisted of: Agnieszka Serafin, PhD., Hanna Warsewicz-Górska, Doctor Habilitatus, Krzysztof Kandefer, PhD, Edyta Łyszkowska, PhD, Maciej Dębski, PhD, Zdzisław Sirojć, Doctor Habilitatus, Jerzy Chorążuk, $\mathrm{PhD}$, a research team from The Maria Skłodowska-Curie Warsaw Academy, and Nonna Borisovna Zinovieva, Prof. and Elena Yakovlevna Galimova, Associate Professor at Krasnodar State University of Culture and Arts agreed on the concept for carrying out a joint survey, which was supposed to be an international comparative study.
} 
In principle it was assumed that both Polish and Russian experts have freedom in the selection of a university. Consequently a decision was made to survey Polish students from the extramural course at university - The Maria Sklodowska-Curie Warsaw Academy and from Russia - also the students from only one university, the Krasnodar State University of Culture and Arts. In both cases surveyed students were attendees of the full course.

The above arrangement and the selection of university had methodological impact on the survey findings. Namely the survey findings are not representative of the opinion of surveyed academic communities in both countries. The researchers were aware of the deficiency of survey findings based on data only with from two universities from the very beginning, when the research project concept was accepted.

Such survey design was driven by the several material premises. It was assumed a priori that the selection of academia research sample was not going to be based on random rule (scheme), but rather it was a result of purposeful selection of universities in both countries. Then the selection of students from both academia was not going to be based on randomly selected sample and will not represent students from both universities. Finally it was assumed that the number of surveyed students at both universities in Poland and Russia, would be approximately around 200.

A part of the survey was concerned with media consumption. The project research problem was worded as follows: Are media consumption patterns similar or different and to what extent?

Are determinants and considerations different in both countries? The following set of research questions was developed:

- Are the students in both countries similar and to what extent? Are they different, and to what extent, in their attitudes and opinions?

- How do they spend their spare time (spare time structure)?

- Do they have their own PC and do they have Web access?

- How much time do they spend in front of a PC and TV set?

- What is the level of addiction to mass media? 
- What information do they search for on the Web and what is the purpose?

The survey had cognitive and analytical dimension and focused on fact examination.

\section{Media in the lives of Poles and Russians - survey findings}

An important issue, which is in the eye of interest of media consumption researchers is the amount of time devoted by the respondents to individual media. In the survey question asked about spare time structure $52 \%$ of Polish female students and 58\% of Russian female students declared that it was their most frequent way of spending their spare time. The rates are much higher in the population of male students: Polish male students - 73\%, Russian male students - 61\%. This implies that media play an important role in the lives of young people and are one of the most time-consuming activities beside the time devoted to taking care of their families and housework. This is confirmed by the analysis of the spare time consumption structure where students were divided into two age categories: below 25 years of age and $26+$ years of age. The survey findings show that both in Poland and in Russia, the highest amount of spare time is consumed by media in the category of students below 25 years of age. For students who are more than 26-years-old family values and house chores are of greater importance.

Respondents in both countries answered the question about the total time devoted to all media on weekdays in the range of 3-4 hours a day. The answers to this question seem not to be compatible with the next question about time devoted to PC. It might have happened that the respondents in both countries did not consider PC to belong to "all media" category. 25.9 \% of surveyed Poles and 23.3\% of surveyed Russians declared that they spend 1-2 hours for all media consumption. 31.4\% of surveyed Poles and $35.3 \%$ of surveyed Russians declared that they spent 3-4 hours for all me- 
dia consumption. 16.2 \% of surveyed Poles and $22.9 \%$ of surveyed Russians declared that they spent 5-6 hours for all media consumption. 18.9 $\%$ of surveyed Poles and $12.9 \%$ of surveyed Russians declared that they spent 7+ hours for all media consumption.

Table 1. Total amount of time spent on consumption of all media on weekdays

\begin{tabular}{|l|l|l|l|l|}
\hline \multirow{2}{*}{} & \multicolumn{2}{|l|}{ Poland } & Russia \\
\cline { 2 - 5 } & No. of resp. & {$[\%]$} & No. of resp. & {$[\%]$} \\
\hline 1. below 1 hour & 14 & $7,6 \%$ & 11 & $5,2 \%$ \\
\hline 2. approx. 1-2 hours & 48 & $25,9 \%$ & 49 & $23,3 \%$ \\
\hline 3. approx. 3-4 hours & 58 & $31,4 \%$ & 75 & $35,7 \%$ \\
\hline 4. approx. 5-6 hours & 30 & $16,2 \%$ & 48 & $22,9 \%$ \\
\hline 5. 7+ hours & 35 & $18,9 \%$ & 27 & $12,9 \%$ \\
\hline Total & 185 & $100,0 \%$ & 210 & $100,0 \%$ \\
\hline
\end{tabular}

Source: own calculations

Media consumption is correlated with age and with marital status. The surveys showed that the lower year of study at university, the more time is devoted to media. This rule applies mainly to the Polish students. Every third Polish student in $1^{\text {st }}, 2^{\text {nd }}$ or $3^{\text {rd }}$ year spends on average 3-4 hours in front of PC. The time distribution in the population of older students is similar: 3-4 hours spent daily in front of PC. Both in the first and in the second time bracket there are approximately $27 \%$ of surveyed students.

In Russia one can observe a rule that the higher year of study, the more time student devotes to the media. $34 \%$ of students attending $1^{\text {st }}, 2^{\text {nd }}$ and $3^{\text {rd }}$ year of studies spend 3-4 hours daily in front of the media and 10 per cent more students attending $4^{\text {th }}$ and $5^{\text {th }}$ year. More than $22 \%$ of younger students (doing their $1^{\text {st }}, 2^{\text {nd }}$ and $3^{\text {rd }}$ year) and almost $30 \%$ of older students (the remaining years) spend approximately 5-6 hours daily in front of the media.

The amount of time spent in front of the media was not influenced by the type of studies, nor place of living (with parents or alone). Meanwhile an essential variable is the lack of partner in life. The surveys con- 
firmed that being single is conducive to seeking oblivion in the media. Both in Poland and in Russia the lack of life partner leads to the situation where spare time is devoted to the media more frequently, whereas married people spent much less time on media.

The most popular media, helpful in learning and used for studying both by the Polish and Russian students, include personal computer (PC). As many as $90 \%$ of Polish students and $84.1 \%$ of the Russian students declared that they use a PC. Meanwhile 96.8\% of the surveyed Polish students and $\mathbf{9 1 . 1 \%}$ of Russian students declared that they use the Internet. Another popular tool allowing to enjoy media technologies is a mobile phone. $66.4 \%$ of Russian students and $42.1 \%$ of Polish students admitted that they use this technology to study. Similar percentages on the application of television to studying were declared both by the Poles (24.7\%) and by the Russians (22\%). The radio is used in Poland by $12.1 \%$ and in Russia by $6.1 \%$, the MP3 player (music) is used by $9.5 \%$ of Polish students and $14 \%$ of Russian students. Tablets are far more popular in the population of Polish students (12.1\%) than among Russian students (5.1\%). Quite interesting is the percentage of people in Russia who declared other technologies (8.4\%), in Poland it was (3.7\%).

The students coming from the rural areas use new technologies more intensively than the students from the urbanized areas. This is the rule applicable to Poland. In Russia that rule is not applicable, namely the media are used more intensively by the students who originate from the city. Both in Poland and in Russia these differences most frequently reach a few per cent, however, a certain recurring trend can be observed.

The amount of time spent in front of a PC grows proportionally in both populations: Russian and Polish students. However, the surveys showed that more Russian than Polish students spent more than 2 hours in front of a PC (88.3\% of Russian students and $73 \%$ of Polish students (Table 2$)$ ). 
Table 2. Amount of time spent in front of PC

\begin{tabular}{|l|l|l|l|l|}
\hline \multirow{2}{*}{} & \multicolumn{2}{|l|}{ Poland } & \multicolumn{2}{l|}{ Russia } \\
\cline { 2 - 5 } & No. of resp. & {$[\%]$} & No. of resp. & {$[\%]$} \\
\hline 1. below 1 hour & 29 & $15,7 \%$ & 5 & $2,3 \%$ \\
\hline 2. approx. 1 hour & 21 & $11,4 \%$ & 20 & $9,3 \%$ \\
\hline 3. approx. 2 hours & 29 & $15,7 \%$ & 52 & $24,3 \%$ \\
\hline 4. approx. 3 hours & 24 & $13,0 \%$ & 62 & $29,0 \%$ \\
\hline 5. 4+ hours & 82 & $44,3 \%$ & 75 & $35,0 \%$ \\
\hline Total & 185 & $100,0 \%$ & 214 & $100,0 \%$ \\
\hline
\end{tabular}

Source: own calculations

Data on single students shows that above $59 \%$ of the Poles and $60 \%$ of the Russians devote more than 3 hours daily to the PC. The number of single Poles (28\%) is by all means much higher than Russians (12\%) who spend relatively less time in front of the PC.

Students who have relationships represent fairly specific group in terms of time spent in front of the PC. Childless young people have more time and also other values are more important for them. Meanwhile in the population of Russians that have relationships more than $93 \%$ spend $2+$ hours of their time in front of PC. This is atypical behaviour, though specific to young people below 25 years of age.

The highest amount of time spent by the students from both countries sitting in front of the PC is devoted to: preparing for classes at the university (Polish students - 72\%, Russian students $-84.7 \%$ ) and searching for information (Polish students - 66.1\%, Russian students - 74,1\%). The highest discrepancy between both countries is the use of PC at work: Polish students account for $62.4 \%$, whereas Russian students - merely $20.8 \%$. Meanwhile Russian students spend much more time (as many as 66.7\% of respondents) on conversation with their friends over Internet (chat) or e-mailing, whereas in Poland it is only every fourth respondent. In Poland the marginal percentage of the respondents admitted computer gaming, meanwhile learning of foreign languages via PC was declared by $12.7 \%$ of respondents. A reverse trend can be observed in the population of Krasno- 
dar students where $11.1 \%$ admitted computer gaming, whereas only $1.3 \%$ of students (Table 3) declared using a PC for learning foreign languages.

Table 3. Utilization of time spent in front of PC

\begin{tabular}{|l|l|l|l|l|}
\hline \multirow{2}{*}{ Option } & \multicolumn{2}{|l|}{ Poland } & \multicolumn{2}{l|}{ Russia } \\
\cline { 2 - 5 } & $\begin{array}{l}\text { No. of } \\
\text { resp. }\end{array}$ & $\begin{array}{l}\text { No. of } \\
\text { resp. }\end{array}$ & [\%] \\
\hline 1. preparing for classes at university & 136 & $72,0 \%$ & 183 & $84,7 \%$ \\
\hline 2. professional work & 118 & $62,4 \%$ & 45 & $20,8 \%$ \\
\hline 3. chatting (or e-mailing) with friends & 47 & $24,9 \%$ & 144 & $66,7 \%$ \\
\hline 4. computer gaming & 11 & $5,8 \%$ & 24 & $11,1 \%$ \\
\hline 5. information search & 125 & $66,1 \%$ & 160 & $74,1 \%$ \\
\hline 6. studying foreign languages & 24 & $12,7 \%$ & 3 & $1,4 \%$ \\
\hline 7. other & 9 & $4,8 \%$ & 12 & $5,6 \%$ \\
\hline
\end{tabular}

Source: own calculations

The PC-related activities vary a great deal not only for the breakdown by gender, but also by the country. The surveys showed that both in Poland and in Russia women are more bothered about class preparation. Class preparation is indicated as the first PC-related activity by the Polish female students (73\%) and by the Russian female students (90\%), and at the second place they mentioned information search on the Web. Both nations vary in terms of their attitude to work and to social life. More than $64 \%$ of Polish women stated that the Internet was a tool of their everyday work (in Russia it was merely 19\%), whereas 66\% of Russian women stated that they use the Internet as a tool for their social life: they chat with friends (in Poland it was only 24\%).

Clearly in Russia social media and chats are widely propagated and deeply rooted in culture, since Russian men use social media to a similar degree and with similar frequency as Russian women do. Almost $47 \%$ of Poles use the Internet in their professional work (in Russia almost $10 \%$ less). What is more, almost $40 \%$ of surveyed Russians admitted that they go intensively for computer gaming. The percentage in Russia is twice as big as surveyed Poles. 
The impact on the quality of time spent in front of $P C$ has also the marital status of respondents. People staying in relationships value higher time spent away from PC, since they access the Internet mainly when they have good reason e.g. to search for information or to get prepared for university classes. Computer gaming or learning of foreign languages attract marginal number of respondents with established relationships. Besides Russian men and women make only an exception for chatting with friends.

Almost every second student in Poland enquired about the use of an e-learningmethodduring theacademicyearadmitted thatheused this method (in Poland itwas 50.3\%, andin Russia 42.6\%). In Russiamuchmorestudents (57.4\%) than in Poland (49.7\%) have not used e-learning method (Table 4).

Table 4. E-learning courses used to learn during the academic year

\begin{tabular}{|l|l|l|l|l|}
\hline \multirow{2}{*}{} & \multicolumn{2}{|l|}{ Poland } & Russia \\
\cline { 2 - 5 } & No. of resp. & {$[\%]$} & No. of resp. & {$[\%]$} \\
\hline 1. Yes & 94 & $50,3 \%$ & 89 & $42,6 \%$ \\
\hline 2. No & 93 & $49,7 \%$ & 120 & $57,4 \%$ \\
\hline Total & 187 & $100,0 \%$ & 209 & $100,0 \%$ \\
\hline
\end{tabular}

Source: own calculations

In Poland every second female and male student used the e-learning method, while in Russia the differences in gender are marginal, whereas the percentage of students interested in e-learning method is approximately $10 \%$ smaller. In Russia the e-learning method does not arouse so much interest as in Poland, however, it is selected by the students in the initial years at university. Contrary to the basic assumption of the e-learning method i.e. it is perfect method for people living in the outskirts of the cities, this method has won the highest popularity among students living in the urban rather than rural areas.

Meanwhile the responses to the question on spending their spare time in front of a TV set turned out to be really astonishing. It has turned out that 
Russian respondents declared much smaller amount of time spent in front of a TV set than their Polish counterparts. The inverse relationship is visible here. More than 54.3\% of Russian students declared that they spent less than 1 hour daily in front of TV set, whereas in Poland such declaration was made by $37.8 \%$ of the respondents. Approximately 1 hour for TV watching is devoted by $21.8 \%$ of Polish students and $22.6 \%$ of the Russian students. Polish students declared two hours of TV watching ( $27.1 \%$ ) and only $13.1 \%$ Russian students did the same. Approximately 3 hours daily of TV watching was admitted by $10.6 \%$ of the Polish respondents and $7 \%$ of Russian respondents. Above 4 hours daily of TV watching was admitted by $3 \%$ of Polish respondents and $3 \%$ of Russian respondents (Table 5).

Table 5. Time devoted to TV watching on a daily basis

\begin{tabular}{|l|l|l|l|l|}
\hline \multirow{2}{*}{} & \multicolumn{2}{|l|}{ Poland } & Russia \\
\cline { 2 - 5 } & No. of resp. & {$[\%]$} & No. of resp. & {$[\%]$} \\
\hline 1. below 1 hour & 71 & $37,8 \%$ & 108 & $54,3 \%$ \\
\hline 2. approx. 1 hour & 41 & $21,8 \%$ & 45 & $22,6 \%$ \\
\hline 3. approx. 2 hours & 51 & $27,1 \%$ & 26 & $13,1 \%$ \\
\hline 4. approx. 3 hours & 20 & $10,6 \%$ & 14 & $7,0 \%$ \\
\hline 5. 4+ hours & 5 & $2,7 \%$ & 6 & $3,0 \%$ \\
\hline Total & 188 & $100,0 \%$ & 199 & $100,0 \%$ \\
\hline
\end{tabular}

Source: own calculations

The TV watching time consumption by young women is similar in both countries. The largest discrepancies can be found in time spending declarations in the category below one hour of TV watching. Only 39\% of Polish women ticked this category compared to 51\% of Russian women. Almost every third Polish woman spends at least two (2) hours on TV watching. The quoted statistics show that Polish women are much more fond of TV watching than Russian women. However, a bigger gap can be observed in the male populations. 
Russian men hardly ever watch television compared to Polish men. 87\% of the Russian men declared that they watch television one (1) hour or less, and merely $13 \%$ of young Russian men watch television for two (2) hours and more. In Poland television watching statistics for men look entirely different. Less than one hour or one hour of TV watching was declared by almost $67 \%$ of Polish men, whereas every third Polish man watches television 2 hours or longer. The above data give testimony about different leisure culture in both countries and other ways of having entertainment in life. In Poland the entertainment is associated with television and the Internet, whereas the Russians prefer other forms of entertainment.

The same values vary a great deal in the population of students categorized by domicile. Most of Russians living in rural areas watch television less than 1 hour daily (almost 74\% of them), whereas in other hour-based TV watching categories the percentages of respondents do not even reach $10 \%$. This implies that the young people are required to help actively in farming or they prefer spending their spare time in other way than watching TV. What is more, Poles from rural areas watch television 1 to 3 hours daily (93\% of them). In the population of Poles coming from urban areas TV consumption is also higher than in Russia.

The question if the students could imagine their everyday life without any indicated technology (mobile phone, television, Internet, iPod, laptop/ PC) aimed at showing high dependency on a certain device, which could indicate initial phase of addition in this area. The students would be plagued the most in their everyday lives by the lack of:

- Mobile phone: $55.7 \%$ of Polish students and $57.8 \%$ of Russian students,

- Internet: $29.5 \%$ of Polish students and 39.6\% of Russian students,

- Laptop/PC: $24.7 \%$ of Polish students and 34.4\% of Russian students.

The respondents would be the most inclined to give up watching TV $(89.2 \%$ of the Poles and $95.3 \%$ of the Russians) and using iPod (95.6\% of the Poles and 92.3\% of the Russians) (Table 8). The survey findings confirm a trend among students from both countries to spend spare time on TV watching (see Table 6). 
Table 6. Declarations of students on an option of not using the specified media technologies

\begin{tabular}{|c|c|c|c|c|c|}
\hline & \multicolumn{2}{|l|}{ YES } & \multicolumn{2}{|l|}{$\mathrm{NO}$} & \multirow{2}{*}{$\begin{array}{l}\text { Total an- } \\
\text { swers }\end{array}$} \\
\hline & No. of resp. & {$[\%]$} & No. of resp. & {$[\%]$} & \\
\hline 1. mobile phone & 81 & $44,3 \%$ & 102 & $55,7 \%$ & 183 \\
\hline 2. television & 165 & $89,2 \%$ & 20 & $10,8 \%$ & 185 \\
\hline 3. internet & 129 & $70,5 \%$ & 54 & $29,5 \%$ & 183 \\
\hline 4. iPod & 172 & $95,6 \%$ & 8 & $4,4 \%$ & 180 \\
\hline 5. laptop /PC & 137 & $75,3 \%$ & 45 & $24,7 \%$ & 182 \\
\hline
\end{tabular}

Russia

\begin{tabular}{|l|l|l|l|l|l|}
\hline \multirow{2}{*}{} & \multicolumn{2}{|l|}{ YES } & \multicolumn{2}{l|}{ NO } & \multirow{2}{*}{$\begin{array}{l}\text { Total an- } \\
\text { swers }\end{array}$} \\
\cline { 2 - 6 } & No. of resp. & {$[\%]$} & $\begin{array}{l}\text { No. of } \\
\text { resp. }\end{array}$ & {$[\%]$} & 211 \\
\hline 1. mobile phone & 89 & $42,2 \%$ & 122 & $57,8 \%$ & 211 \\
\hline 2. television & 201 & $95,3 \%$ & 10 & $4,7 \%$ & 212 \\
\hline 3. internet & 128 & $60,4 \%$ & 84 & $39,6 \%$ & 208 \\
\hline 4. iPod & 192 & $92,3 \%$ & 16 & $7,7 \%$ & 210 \\
\hline 5. laptop /PC & 138 & $65,7 \%$ & 72 & $34,3 \%$ & \\
\hline
\end{tabular}

Source: own calculations

The above table shows that Russian female students use mobile phones more than their Polish counterparts and could not live without them. However, they are less addicted to television, but more addicted to the Internet than Polish female students. The survey findings showed that the Russians spend less time on TV watching. The Russian men are more addicted to Internet and music listening than to television. Poles in turn could not cope without mobile phones and Internet (however, to a smaller extent than the Russians), and they also tend to spend a lot of time on TV watching. It is interesting to note that both young people in Poland and in Russia coming from rural areas tend to spend more spare time with the media. Russian respondents in this category have proportionally more declarations than Polish respondents. Perhaps the students coming from urban areas are brought up on the grounds of other cultural patterns and spend their spare time differently than their counterparts coming from the rural areas. 


\section{Final remarks}

The analysis of media and new technology consumption in everyday life shows that students in both countries tend to enjoy spending their spare time in a similar manner. More than $50 \%$ of students in each country spend their spare time in front of a PC or consuming other media. Also the percentage structure of the amount of time consumed using the media is similar: the differences are visible only when the structure is broken down into individual relationships.

The main tool for work and for contacting other people, both for Polish and Russian students, is personal computer (PC), which is also used to prepare for classes at university. However, for Russian students the PC is also entertainment centre and is used far more often for socializing.

The e-learning method is much more popular in Poland than in Russia. Both countries use e-learning method with various degrees of intensity at individual years of studies at university. Respondents' declarations on their time spent on TV watching are surprising. It seems that in Poland higher number of respondents devote their time to watching TV than in Russia. Higher addiction to media is shown by the students coming from rural rather than urban areas. These results are still better than in similar social groups, however, the fact of such high disproportions is quite disturbing. Higher amount of spare time spent on watching TV and consumption of other media means less time spent on real entertainment (forms of entertainment enjoyed in real time). The respondents in both countries disclosed their habits on the consumption of mobile phone, Internet and laptop. We can observe similar trends in other research of European students (Zawacki-Richter, Müskens, Krause, Alturki, Aldraiweesh, 2015).

However, the addictions of the students coming from the rural areas look differently-we can notice here a significant trend to spend one's spare time with a mobile phone and the Internet. Proportionally a high number of 
students showed symptoms of early addiction to media. We can observe similar trends in other research of the European students.

The surveys discussed here represent a material contribution to the approach to the $21^{\text {st }}$ century consumer, a consecutive generation of young people that are on the threshold of their professional lives. They show habits and opinions of young people in the field of quickly evolving consumption of media technologies. 


\section{Bibliography:}

Brydolf, C. (2007) Minding MySpace: Balancing the benefits and risks of students'

online social networks. Education Digest, 73(2), 4.

Chocholska, P., Osipczuk, M., (2009) Uzależnienie od komputera i Internetu u dzieci i młodzieży (Computer and Internet Addiction in Children and Youth Populations), Hachette Poland, Warszawa.

Dębski M. (2013), Quality as an element of creating destination brand, Contemporary Management Quarterly. The Journal of Scientific Community and Business Leaders, 1.

Gerlich, R., Browning, L., Westermann, L. (2010) The social media affinity scale: implications for education. Contemporary Issues in Education Research, 3(11).

Jacobsen, W.C., Forste, R. (2011) The Wired Generation: Academic and Social Outcomes of Electronic Media Use Among University Students, Cyberpsychology, Behavior, and Social Networking 14 (5).

McQuail, D., (2007) Teoria komunikowania masowego (Mass Communication Theory), Wydawnictwo Naukowe PWN, Warszawa.

Szafraniec, K., (2012) Konsumpcja, czas wolny, nowe media-obszary manifestacji statusu i własnego "Ja"(Consumption, Spare Time, New Media-Areas for Manifestation of Status and Own Self) [in:] Lider. Promocja zdrowia, kultura zdrowotna i fizyczna (Leader. Health Promotion, Health and Physical Culture), No. 2 (252).

Wallace, P., (2005) Psychologia Internetu (Internet Psychology), Nowe Horyzonty, Poznań.

Netography:

ICT Fact \& Figures, (2015), http://www.itu.int/en/ITU-D/Statistics/Documents/facts/ ICTFactsFigures2015.pdf

Landowska, M., (2012), Czy koncepcja McKinsey Consumer Journej zastąpi tradycyjny lejek sprzedaży, (Is McKinsey Consumer Journey Concept Going to Replace Conventional Sales Funnel) https://www.linkedin.com/grp/post/1869560178065195, 23 October, [10.09.2015]. 
United Nations Cyberschoolbus (2013), Raport dla inwestorów, (Investor Report) // www.fb.com [10.09.2015]

World Internet Project Poland (2013), http://metro.gazeta.pl/Portfel/1,135229,14894700, Co_jest_wazniejsze ____ Internet_czy_telewizja Najwazniejsze.html (What Is the More Important_Internetor Television) [20.08.2015].

Zawacki-Richter, O., Müskens, W., Krause, U., Alturki, U., Aldraiweesh, A., (2015), Student Media Usage Patterns and Non-Traditional Learning in Higher Education, http:// www.irrodl.org/index.php/irrodl/article [20.11.2015] 